\title{
A segunda contradição do capitalismo e o sonho do Estado de Direito Ambiental
}

\author{
Capitalism's second contradiction and the dream of a State of \\ Environmental LaW
}

$10.21680 / 1983-2109.2021 \mathrm{v} 28 n 56$ ID23501

\author{
Vanessa de Castro Rosa \\ Universidade do Estado de Minas Gerais (UEMG) \\ 0000-0002-8370-0373 \\ vanisros@hotmail.com
}

\begin{abstract}
Resumo: A busca de um Estado de Direito Ambiental para promoção do modelo de desenvolvimento sustentável que concilie a questão ambiental, social e econômica, está longe de se mostrar como medida efetiva para a solução da crise ambiental que assola o planeta. Verifica-se nos últimos anos uma profusão de leis ambientais e em velocidade ainda maior uma aceleração dos problemas ambientais, o que mostra um nítido descompasso entre leis ambientais, Estado ambiental e destruição da natureza. O elemento central deste compasso está no capitalismo e em suas contradições, o que torna inviável a efetivação de medidas ambientais diante da lógica acumulativa e depredatória que o sustenta, descrita na segunda contradição do capitalismo. $O$ objetivo do presente trabalho é destacar o papel do Estado de Direito Ambiental e verificar sua compatibilidade estrutural com o funcionamento do capitalismo, a partir do referencial teórico marxiano e de autores como James O'Connor, John Bellamy Foster e Michael Löwy. A pesquisa é teórica, crítico-descritiva, realizada por técnica bibliográfica.
\end{abstract}

Palavras-chave: Estado de Direito Ambiental; Capitalismo; Segunda Contradição.

\begin{abstract}
The search for a State of Environmental Law to promote the sustainable development model that reconciles the environmental, social and economic issue, is far from showing itself as an effective measure for the solution of the environmental crisis that is plaguing the planet. In recent years there has been a profusion of environmental laws and at an even greater speed an acceleration of environmental problems, which shows a clear mismatch between environmental laws, environmental status and destruction of nature. The central element of this measure is capitalism and its contradictions, which makes the implementation of environmental measures unfeasible in the face of the accumulative and depredatory logic that sustains it, described in the second contradiction of capitalism. The aim of this paper is to highlight the role of the State of Environmental Law and verify its structural compatibility with the functioning of capitalism, based on the Marxian theoretical framework and authors such as James O'Connor, John Bellamy Foster and Michael Löwy. The research is theoretical, critical-descriptive, performed by bibliographic technique.
\end{abstract}

Keywords: State of Environmental Law. Capitalism. Second Contradiction. 


\section{INTRODUÇÃO}

A imposição de uma monocultura tóxica que envenena a população, a disseminação dos transgênicos, sem preocupação com as próximas gerações, a exploração do trabalho escravo, a expulsão dos agricultores de suas terras, a extinção de animais e vegetais, o extermínio da população indígena para expansão da fronteira agrícola, a contaminação dos recursos hídricos e o aumento dos casos de câncer causados por agrotóxicos, a desertificação de solos, o patenteamento de sementes, o suicídio de agricultores, a perda da soberania alimentar, entre tantos outros problemas socioambientais podem ser elencados como exemplos do fracasso do direito em ser instrumento de proteção ambiental.

De igual modo, a busca pela construção de um Estado de Direito Ambiental ou Estado Ecológico tenta criar um ordenamento jurídico que preserve o ambiente e se mostre como indutor de um modelo de desenvolvimento sustentável, que concilie harmonicamente a questão ambiental, social e econômica.

Contudo, a partir da compreensão do funcionamento do modo de produção capitalista, seu funcionamento e seu desenvolvimento histórico, constata-se a impossibilidade teórica e prática de se buscar um modelo de desenvolvimento sustentável dentro do capitalismo, consequentemente, as tentativas jurídicas tem-se mostrado inviáveis para tal fim.

Isto porque não há como estancar o processo de exploração da natureza, apenas na esfera normativa, sem enfrentar o modo de produção que impulsiona a acumulação de capital, a produção e consumo em escala ascendentes, a valorização do valor, as trocas a partir do valor de troca (e não valor de uso) e na dissociação entre ser humano e natureza e entre ciência e conhecimento tradicional.

O objetivo do presente trabalho é destacar o papel do Estado de Direito Ambiental e verificar sua compatibilidade estrutural com o funcionamento do capitalismo, a partir do referencial teórico marxiano e de autores como John Bellamy Foster e Michael Löwy. A pesquisa é teórica, crítico-descritiva, realizada por técnica bibliográfica.

\section{ESTADO DE DIREITO AMBIENTAL}

A noção atual de Estado de Direito Ambiental ou Estado Ecológico tem sido trabalhada por organismos internacionais como a World Commission on Environmental Law of International Union for Conservation of Nature (IUCN) e por 
importantes e respeitáveis autores como José Rubens Morato Leite e Joaquim José Gomes Canotilho.

Assim, "o Estado de direito, hoje, só é Estado de direito se for um Estado protector do ambiente e garantidor do direito ao ambiente; mas o Estado ambiental e ecológico só será Estado de direito se cumprir com os deveres de juridicidade impostos à actuação dos poderes públicos" (CANOTILHO, 2007, p. 4-5).

Nesta concepção de Estado de direito deve ser mais que um Estado democrático e social, deve se pautar em princípios ambientais e ecológicos para a condução política e jurídica do Estado, aliada a um novo modelo de participação política e democrática, local e global (CANOTILHO , 2004, p. 3-4), tendo em vista que o meio ambiente transcende as fronteiras políticas e econômicas.

O Estado Ecológico de Direito busca dar maior proeminência ao direito ambiental, a fim de garantir o equilíbrio ecológico e consequentemente as diferentes formas de vida no planeta, a questão ambiental passa a ser o centro das decisões políticas e jurídicas, a fim de dar real efetividade ao direito ambiental.

Neste sentido,

O Estado Ecológico de Direito, pauta-se por um conjunto de normas, princípios e estratégias jurídicas necessárias para garantir a preservação de um conjunto de condições de funcionamento do sistema terrestre que tornam o Planeta Terra um espaço seguro, para o Homem e os restantes seres vivos. A promoção da segurança e da prosperidade humana dentro do espaço operacional seguro é essencial para a manutenção da resiliência sócio-ecológica e para a realização dos objetivos globais de desenvolvimento sustentável (ARAGÃO, 2017, p. 22).

O Estado de Direito Ambiental pauta-se na construção democrática de uma sociedade ecologicamente equilibrada, com uma redefinição do papel do Estado, a fim de privilegiar a ampla participação popular na condução de suas políticas, colocando a obrigação de preservar o meio ambiente como uma obrigação efetiva.

Todavia, o Estado Ambiental é ainda apenas um conceito acadêmico, pois não é possível afirmar que o Estado tenha adotado a proteção ambiental como parâmetro para as suas decisões, nem houve uma "mudança de paradigmas", nem a adoção do princípio da prevenção na gestão do Estado (KRELL, 2017, p. 45).

Mesmo após a adoção da obrigação ambiental no art. 225 da Constituição da República e de uma imensa proliferação de leis ambientais no direito brasileiro, os problemas ambientais continuam existindo e piorando, basta se lembrar do avanço da fronteira agrícola sobre o cerrado, com devastação, extinção de flora e fauna, contaminação e privatização dos recursos hídricos, o que evidencia uma falha da proteção ambiental via legislativa. 
A legislação ambiental torna-se meramente simbólica, isto porque não tem a força para quebrar as estruturas econômico-sociais que impõem um modelo de desenvolvimento depredatório do ponto de vista social e ambiental.

É desalentadora a desventura de um Estado que, não raras vezes, cria dispositivos legais sem o menor compromisso e responsabilidade para com sua efetiva aplicação, simplesmente os desenvolve para dar uma satisfação à sociedade com o fito de apregoar que algo foi feito para esta ou aquela demanda social em pauta, estabelecendo uma legislação simbólica, com o deslavado propósito de instituí-la para servir como um placebo social, com fins ansiolíticos (PACHECO, 2015, p. 310).

Neste sentido, Antônio Herman de Vasconcellos e Benjamin reconhece a teatralidade da proteção ambiental pelo Estado,

É comum o Poder Público legislar, não para aplicar, mas simplesmente para aplacar, sem resolver, a insatisfação social. É o Estado teatral, aquele que, ao regular a proteção do meio ambiente, mantém uma situação de vácuo entre a lei e a implementação. Um Poder Público que, na letra fria do texto normativo, não se importa em bravejar, mas que fácil e rapidamente amansa diante das dificuldades da realidade político-administrativa e de poderosos interesses econômicos, exatamente os maiores responsáveis pela degradação ambiental. A teatralidade estatal é a marca dessa separação entre lei e implementação, entre a norma escrita e a norma praticada. O resultado é uma Ordem Pública Ambiental incompleta (BENJAMIN, 2010, p. 7).

Por esta razão, a norma ambiental é apenas o primeiro passo no processo de proteção do meio ambiente, sendo que muitos estudiosos do direito e ambientalistas, por vezes, consideram a lei como a grande conquista na defesa do meio ambiente, o que não está correto, pois a promulgação da lei não garante sua aplicação, sendo que frequentemente as leis ambientais são promulgadas não para resolver um conflito, mas sim para aplacar uma insatisfação social (BENJAMIN, 2010, p. 7), num verdadeiro direito ambiental simbólico, desprovido de eficácia e efetividade.

Nesta linha, o problema da ineficácia e inefetividade da lei ambiental seria uma questão de implementação, de modo que o desenvolvimento acadêmico de uma teoria da implementação poderia criar mecanismos para efetivação da lei, seja através de implementação direta (por exemplo, licenciamento, padrões de controle, sanções administrativas) ou por implementação indireta (objetivos e princípios do direito ambiental) (BENJAMIN, 2010, p. 36).

Acrescente-se, também, a esta teatralidade estatal da proteção ambiental, a falha proteção jurídica, já que o Supremo Tribunal Federal julgou constitucional os retrocessos do novo Código Florestal, diminuindo as áreas de preservação per- 
manente e anistiando desmatadores, através de articulações imbricadas de palavras e princípios que esvaziam o sentido de proteção ambiental para as presentes e futuras gerações.

Assim, a corte suprema afastou o princípio da proibição de retrocesso socioambiental, sob o argumento de que nenhum princípio é absoluto, e que o direito não pode engessar a ação legislativa e administrativa, ou seja, claramente, o direito se despe de seu papel protetivo, de transformador da realidade e promotor de justiça social e se coloca abaixo dos outros Poderes e outros interesses.

Nesta esteira, o voto do Ministro Celso de Melo, citando a Ministra Carmem Lúcia, enfraquece a norma ambiental, mas avisa que em caso de desrespeito aos direitos socioambientais caberá sempre rigoroso controle de constitucionalidade para a suposta defesa do ambiente e dos demais direitos sociais.

Vale conferir,

[...] a aplicação do princípio da proibição de retrocesso socioambiental não pode engessar a ação legislativa e administrativa, sendo forçoso admitir certa margem de discricionariedade às autoridades públicas em matéria ambiental. Todavia, as medidas que restringem direitos sociais ou ecológicos devem ser submetidas a um rigoroso controle de constitucionalidade que avalie sua proporcionalidade e sua razoabilidade, bem como seu respeito ao núcleo essencial dos direitos socioambientais, sob pena de irreversibilidade dos prejuízos às presentes e futuras gerações (BRASIL, 2018).

Embora as palavras carreadas apontem para a necessidade de se proteger o meio ambiente em seu núcleo essencial para a garantia do direito às futuras gerações, a aludida decisão fez exatamente o contrário, reduzindo drasticamente a proteção ambiental das florestas, sob o argumento de que não se pode engessar a ação legislativa e administrativa, permitindo verdadeiro retrocesso ambiental via legislativa.

Neste ponto, o problema não parece ser de implementação, mas sim político-econômico diante dos interesses que estavam envolvidos no julgamento das ações diretas de inconstitucionalidade do novo Código Florestal, o que mostra claramente o papel do Estado e do direito na defesa de interesses econômicos de classes dominantes.

Outros exemplos, podem ser destacados como a concentração de renda e terras, a assustadora desigualdade social que garante que $1 \%$ (um por cento) da população detenha a mesma quantidade de riqueza dos outros $99 \%$ (noventa e nove por cento) restantes da humanidade (OXFAM, 2017, p. 3), embora haja um 
corpo jurídico de tratados internacionais de direitos humanos que mencionem valores como igualdade, justiça social, saúde, dignidade, alimentação, etc.

Neste cenário, a física e ambientalista Vandana Shiva há tempos vem denunciando o quadro de desigualdade e insustentabilidade deste modo de vida capitalista:

A ganância e a apropriação do quinhão das outras pessoas de seus preciosos recursos planetários são a raiz dos conflitos e a raiz do terrorismo. Quando o presidente Bush e o primeiro-ministro Tony Blair anunciaram que o objetivo da guerra global ao terrorismo é a defesa do "modo de vida" norte-americano e europeu, eles declararam guerra ao planeta - seu petróleo, sua água, sua biodiversidade. Um modo de vida para os vinte por cento das pessoas do planeta que utilizam oitenta por cento dos seus recursos irá privar oitenta por cento da população de sua justa parte dos recursos e, ao fim, destruir o planeta (SHIVA, 2006, p. 14).

O avanço do capitalismo na agricultura moderna separou os seres humanos da terra, expulsou os camponeses, expropriando sua terra e explorando-a até seu exaurimento, mediante uso de agroquímicos e mecanização de grande porte. É um cenário de exploração humana e ambiental.

Esta situação é possível pela atuação direta do Estado, que por sua política creditícia favorece o grande agricultor, detentor do latifúndio monocultor produtor de commodities, em detrimento do pequeno agricultor, que não tem condições de concorrer em condições semelhantes no mercado, restringindo-se a produção alimentícia, que apesar de todas as dificuldades, é a responsável pela alimentação da população humana.

Além disso, as leis garantem o caráter sacramental da propriedade privada da terra, enquanto milhões de pessoas vivem sem terra, bem como a apropriação e mercantilização da natureza, tais como, a privatização dos recursos hídricos, o patenteamento de sementes e técnicas agrícolas (cultivares) e o preço inacessível de alimentos cada vez menos nutritivos e prejudiciais à saúde humana, contribuindo para que atualmente existam mais pessoas famintas no mundo do que havia em 1950, no início da "revolução verde".

\section{MITO DA SUSTENTABILIDADE}

O conceito de sustentabilidade surgiu a partir do desenvolvimento da consciência ambiental no mundo, na década de 1960 e 1970, em decorrência dos grandes desastres ambientais (vazamentos de petróleo no mar, acidente de Chernobyl, Bophal, Seveso), da atuação de organização não governamental Greenpeace que 
divulgou e mobilizou a opinião pública diante das catástrofes ambientais, e tendo como palco a realização das Conferências das Nações Unidas para a proteção ambiental.

Em 1992, o Brasil sediou a Conferência das Nações Unidas sobre o Meio Ambiente e o Desenvolvimento, também conhecida como Eco-92 ou Cúpula da Terra, cujo tema central foi o desenvolvimento sustentável pautado no Relatório Brundtland ou "Nosso Futuro Comum", publicado em 1987, para guiar a Conferência de 1992.

Neste relatório, não há uma definição de desenvolvimento sustentável, mas trabalha com a ideia de se conciliar desenvolvimento econômico e proteção ambiental para as presentes e futuras gerações.

O desenvolvimento sustentável busca conciliar os seres humanos e natureza, através da criação de um sistema político com participação real dos cidadãos no processo decisório; um sistema econômico capaz de gerar excedentes e conhecimento técnico em bases confiáveis; um sistema social capaz de resolver as tensões causadas por um desenvolvimento predatório; um sistema de produção que respeite a obrigação de preservar a base ecológica do desenvolvimento; um sistema tecnológico em constantemente atualização com tecnologia limpa e um sistema internacional que estimule padrões sustentáveis de comércio e financiamento mundiais, pois o meio ambiente está além de fronteiras (COMISSÃO MUNDIAL SOBRE MEIO AMBIENTE E DESENVOLVIMENTO, 1991, p. 70).

O conceito de desenvolvimento sustentável é aberto, não conta com uma definição pronta e acabada, aliás, é extremamente plástico e de difícil compreensão, pois pode aceitar qualquer coisa que em tese seja durável. Mas a doutrina busca conferir uma base mínima sobre a qual possa se erigir uma concepção que conecte desenvolvimento e meio ambiente.

Mas não é somente buscar humanizar ou esverdear a economia,

[...] Possui a dimensão crítica da necessidade de coexistência e coevolução dos seres humanos entre si e com as demais formas de vida do planeta, além de ser também concebido como um novo paradigma que relaciona aspirações coletivas de paz, liberdade, melhores condições de vida e de um meio ambiente saudável (CAMARGO, 2003, p. 15).

No direito brasileiro, o desenvolvimento sustentável tem o status normativo de princípio constitucional implícito, decorrente do artigo 225 combinado com o artigo 170, VI (defesa do meio ambiente na ordem econômica) e princípio ambiental expressamente previsto na Declaração do Rio de 1992, mas sem uma definição 
quanto ao seu conteúdo, apenas apontando a necessidade de desenvolvimento das presentes e futuras gerações (AMADO, 2019, p. 88).

O desenvolvimento sustentável é, comumente, definido sob uma tríplice dimensão: social, ecológica e econômica, também polêmicas, sendo a dimensão social, a mais difícil, na visão de Guilhermo Foladori, pois muitas vezes ela é tratada como meio para se atingir a dimensão ecológica, de modo que

Muitas vezes, as capacidades humanas e as relações sociais que dizem respeito à forma como se gera a pobreza e o desemprego não estão em discussão, senão somente suas consequências técnicas enquanto poluição e degradação dos ecossistemas (FOLADORI, 2002, p. 107).

Questões sociais são colocadas como meio para se alcançar a sustentabilidade ecológica, de modo a excluir muitos problemas sociais, por não terem "relação direta" com a questão ecológica. Esta visão unidimensional despreza o elemento humano do ambiente, principalmente, os mais vulneráveis, o que não é sustentável, pois muitos dos problemas sociais que atingem os pobres são também problemas ecológicos.

Os problemas econômicos são problemas sistêmicos e, portanto, precisam ser pensados e resolvidos a partir do pensamento sistêmico, que é um pensamento ecológico, de modo que para manter um sistema econômico num estado de equilíbrio dinâmico, é crucial preservar a flexibilidade ecológico do ambiente e criar flexibilidade social necessária para adaptação às mudanças ambientais (CAPRA, p. 380,383$)$.

Para se pensar em sustentabilidade é necessário compreender a dinâmica do capital, a fim de que se possa quebrar estas formas de opressão e exploração, pois "o capitalismo tem uma base ideológica que se conjugará num duplo processo de exploração: o homem explorando o homem e o homem explorando a natureza" (PELIZZOLI, 1999, p. 132).

A sustentabilidade significa o desejo de se buscar soluções para a crise ambiental, portanto, é necessário compreender a natureza desta crise. A crise ambiental não é um fenômeno isolado restrito aos elementos da natureza, ela é produto das ações humanas e do modo de produção capitalista.

A crise econômica e a crise ecológica resultam do mesmo fenômeno: um sistema que transforma tudo - a terra, a água, o ar que respiramos, os seres humanos - em mercadoria, e que não conhece outro critério que não seja a expansão dos negócios e a acumulação de lucros. As duas crises são aspectos interligados de uma crise mais geral, a crise da civilização capitalista industrial moderna. Isto é, a crise de um modo de vida - cuja forma caricatural é o famoso american way of life, que, obviamente, só pode existir enquanto for privilégio de uma minoria - de um sistema de produção, 
consumo, transporte e habitação que é, literalmente, insustentável (LÖWY, 2013, p. 79-80).

Por exemplo, a migração de população em virtude de catástrofes naturais, fenômeno batizado de refugiados ambientais, embora seja um problema social, sua base está num problema ecológico, que se desdobra em outros problemas políticos e econômicos, cujas raízes remontam a exploração capitalista numa dinâmica global.

A sustentabilidade deve ser pensada em suas três dimensões conjuntamente, para a devida compreensão do problema e para a busca de soluções adequadas e efetivas, ou seja, não adianta focar apenas em soluções tecnológicas, pois os problemas são sociais, econômicos e ecológicos.

Como também, não é possível buscar soluções para problemas coletivos, a partir de ações individuais. Desta forma,

A grande questão em torno da sustentabilidade social continua sendo o fato de esse conceito se restringir a mudanças técnicas, que podem melhorar significativamente o nível e a qualidade de vida em nível local, ou para determinados setores, porém, e como escrevem Middleton e O'Keefe, dois expertos em projetos de desenvolvimento, não há como atacar a justiça social sem afetar as relações de propriedade. No instigante livro Redefining Sustainable Development(2001), esses autores colocam explicitamente a contradição-chave: enquanto os problemas de pobreza, justiça social e sustentabilidade social em termos gerais são resultados sociais, de uma forma de distribuição e propriedade dos recursos e dos meios de produção, os discursos mais avançados do desenvolvimento sustentável, ou as práticas das ONGs de maior compromisso com esses discursos, continuam a trabalhar a partir da ótica do indivíduo (FOLADORI, 2002, p. 112).

Não é possível pensar em sustentabilidade, sem resolver questões sociais que estão no âmago da exploração capitalista, até porque a questão ambiental é também social e econômica. Todavia, o sistema capitalista é organizado sobre a exploração dos seres humanos e da natureza, gerando degradação ambiental, miséria e desigualdade social, o que não se coaduna com conceitos de sustentabilidade.

Neste sentido, István Mészáros esclarece que é impossível desenvolvimento sustentável com desigualdade social, ou seja, sem igualdade substantiva,

O maior desafio do desenvolvimento sustentável, que agora devemos enfrentar, não pode ser devidamente tratado sem a remoção dos constrangimentos paralisantes de carácter adverso do nosso sistema de reprodução. Esta é a razão porque não pode ser evitada a questão da igualdade substantiva no nosso tempo como o foi no passado. Por sustentabilidade significamos o estar realmente no controle dos processos culturais, econômicos e sociais vitais através dos quais os seres humanos não só sobre- 
vivem mas também podem encontrar satisfação, de acordo com os objetivos que colocam a si mesmos, em vez de estarem à mercê de imprevisíveis forças naturais e quase-naturais determinações socioeconômicas (MÉSZÁROS, 2001, não paginado)

Destarte, a sustentabilidade em sua tripla dimensão não se mostra possível no capitalismo, pois ele se mantém através de um processo dinâmico de acumulação, o qual é portador de crises e colapsos, ou seja, é um processo de acumulação de capital que é simultaneamente uma "luta de classes, luta pela produção e apropriação do sobreproduto, [estando] permanentemente sujeito a paralisações e colapsos" (HIRSCH, 2010, p. 33).

O chamado Estado de Bem-Estar Social não logrou êxito em frear os excessos capitalistas de exploração e degradação ambiental, nem em alcançar patamares mínimos de justiça social, tanto que $20 \%$ da população mundial consome $80 \%$ da matéria e da energia produzidos na Terra (PELIZZOLI, 1999, p. 133).

O Estado Social trouxe bem-estar para poucos e extremou os limites de produção e exploração da natureza, colocando em risco a existência de vários recursos naturais, como espécimes de flora, fauna, água e solo e deixando milhões de pessoas na miséria, ou seja, a ilusão do progresso econômico alardeada pelo capitalismo produziu consumismo para poucos e crise ecológica para todos.

Este desequilíbrio social e ecológico promovido pelo Estado de Bem-Estar Social pode ser visualizado através dos seguintes números: para que todos tenham um padrão de vida como o europeu, seria necessário 23 vezes mais energia, 10 vezes mais produção de combustíveis fósseis, 90 vezes mais riquezas minerais, duas vezes a quantidade de terra agriculturável - ou seja, outro planeta Terra (PELIZZOLI, 1999, p. 96).

Assim, pensar em um sistema agroecológico como sistema produtivo requer alteração na estrutura da sociedade e não apenas no direito, aliás, o direito só mudará quando as próprias estruturas sociais mudarem, pois ele sempre caminha a reboque das transformações e invenções sociais.

Num sistema cuja lógica de produção e acumulação são ilimitadas, não há como se pensar em produção limpa, ou em sustentabilidade. Dentro do capitalismo estas formas "verdes" ou "limpas" de produção são pontuais, não sendo aptas a substituir todo o modo de produção capitalista, pois este necessita de uma produção crescente, logo, "não haverá a tão prometida 'reconciliação entre economia e ecologia"” (MANDEL apud ANDRIOLI, 2008, p. 18).

Neste sentido, 
Mediante a predominância da troca de mercadorias e do lucro, as relações entre os seres humanos e a natureza passam a ser monetarizadas. Uma outra consequência resultante disso é a particular combinação de uma racionalidade parcial (uma racionalidade instrumental baseada no mercado) e uma irracionalidade global. A lógica limitada da maximização dos lucros e o produtivismo dela resultante evidenciam que a ideia de um "capitalismo sustentável" orientado para o mercado é ilusória (ANDRIOLI, 2008, p. 18).

O mercado capitalista não é um sistema homeostático, a força que move o mercado é a lei da acumulação de capital, que age na esfera de produção de mercadorias e é por definição expansiva, razão pela qual se afirma que "o tamanho ideal do mercado capitalista é, por definição, o infinito” (MARQUES, 2015, p. 476).

Na mesma linha, István Mészáros destaca que o crescimento capitalista independe das necessidades humanas e é guiado pelas mistificações fetichistas, de modo que a busca incessante de crescimento e produtividade é incompatível com o objetivo de sustentabilidade e readequação da produção às necessidades humanas, pois "a preocupação real do capital só pode ser a sua própria eterna expansão ampliada, mesmo se isto trouxer consigo a destruição da humanidade" (MÉSZÁROS, [20-?], não paginado.)

Esta vocação para a produção ilimitada desestrutura o ecossistema, pois são incompatíveis, tendo em vista o caráter limitado e sistêmico (interdependente) dos bens naturais. E o esgotamento dos bens naturais, consequência do capitalismo, torna-se este modo de produção insustentável.

O ponto de partida para a análise da crise ambiental contemporânea está na própria produção mercantil. Enquanto a produção pré-capitalista, de valores de uso, tem seu limite na satisfação das necessidades; a produção mercantil, para incrementar o lucro, não tem limite algum. Esta diferença, tão sensível e geral, está na base do esgotamento dos recursos naturais a um ritmo nunca suspeitado na história da humanidade; e também da generalização de dejetos (poluição) numa medida ilimitada (FOLADORI, 1999, p. 89.)

Luiz Marques destaca que a questão da insustentabilidade do capitalismo pode ser comprovada em seis aspectos: a) a economia não é circular ou ecoeficiente, b) a lei da pirâmide de recursos de Heinberg, c) incapacidade do Estado em impor regras ambientais que diminuam o lucro das grandes corporações, d) impossibilidade de internalizar o custo ambiental, e) investimentos em lobbies e publicidade e f) investimentos em censura e desinformação (MARQUES, 2015, p. 482-488).

Os defensores do capitalismo sustentável acreditam que a ecoeficiência de tecnologias permitirá aumentar a produção e o consumo com menor pressão sobre o meio ambiente, porém, esta crença desconsidera o “paradoxo de Jevons' ou 
efeito rebote (rebound effect) [que] descreve o aumento da demanda por energia ou por recursos naturais sempre tende a compensar o ganho de ecoeficiência da inovação tecnológica" (MARQUES, 2015, p. 482). Isto significa que embora a tecnologia seja ecoeficiente e economize energia, o volume de produção cada vez maior anula esta economia energética.

Por esta razão, Georgescu-Roegen, considerado o precursor da economia ecológica, afirma que a economia não é um sistema fechado, por depender de recursos naturais, produzir resíduos e afetar a quantidade de materiais e energia das futuras gerações, por isto, a utilização e depleção dos recursos naturais, a produção de resíduos e a poluição são o "cerne do problema ecológico da humanidade" (CECHIN; VEIGA, 2010, não paginado).

Deste modo, a economia não pode lidar com o problema do impacto da produção de bens e resíduos sobre as gerações futuras, por se considerar um sistema fechado desconectado do ambiente e da natureza, ignorando em seus modelos matemáticos a situação da natureza a longo ou longuíssimo prazo (CECHIN; VEIGA, 2010, não paginado).

A questão ecológica é também uma questão socioeconômica e de igual peso remete a uma questão de paradigma filosófico, cultural e ético, de modo que não há como se falar em sustentabilidade olvidando-se de questões sociais.

Neste sentido, não existe um único modelo de desenvolvimento sustentável, mas o modelo capaz de enfrentar com novas soluções a crise socioambiental é aquele que parte de gestão democrática da diversidade, com prioridade nas questões sociais, transformando os excluídos e marginalizados em cidadãos (ALMEIDA, 1997, p. 53).

É necessário que a economia seja englobada pela ecologia, porém, "isso só ocorrerá quando a humanidade tiver que se preocupar com a distribuição intertemporal dos escassos recursos terrestres, e não apenas com a alocação de recursos relativamente escassos de uma geração apenas" (CECHIN; VEIGA, 2010, não paginado).

A lei da pirâmide de recursos de Heinberg indica que a necessidade de produção em grande escala anula os esforços de tecnologia limpa ou "verde", os exemplos dados, são os seguintes: a) a escassez de recursos hídricos leva a criação de obras faraônicas de engenharia, cujos impactos ambientais são maiores; b) a perda de fertilidade dos solos aumenta o uso de fertilizantes e o avanço da fronteira agrícola sobre as florestas; c) a diminuição das reservas de terras-raras chinesas leva a 
exploração ambiental para outros países, inclusive o fundo do mar e d) a manipulação genética das plantas em busca de produtividade acarreta o aumento do uso de agrotóxicos, o surgimento de superpragas (MARQUES, 2015, p. 484).

Estes exemplos comprovam a lei da pirâmide de recursos de Heinberg, a qual pode ser enunciada da seguinte forma: "no capitalismo, a escassez crescente de recursos naturais redunda em agravamento do impacto ambiental da atividade econômica" (MARQUES, 2015, p. 484-485).

O terceiro aspecto da insustentabilidade do capitalismo diz respeito a impossibilidade de o Estado se contrapor aos interesses das grandes corporações, a fim de impor uma legislação ambiental. E mesmo se o fizesse, tais medidas ficariam apenas no plano legislativo, pois as empresas conseguem retardar ou tornar ineficazes tais leis diante da protelação.

Neste sentido, Michael Löwy destaca

O problema é que as propostas feitas pelas correntes dominantes da ecologia política europeia são muito insuficientes ou levam a becos sem saída. A sua principal fraqueza é ignorar a conexão necessária entre o produtivismo e o capitalismo, o que leva à ilusão do "capitalismo limpo" ou de reformas capazes de lhe controlar os "excessos" (como, por exemplo as eco-taxas) (LÖWY, 2005, p. 46).

O quarto aspecto refere-se à impossibilidade de se internalizar o custo ambiental, "pois o valor total gerado por sua atividade é, com frequência, menor que o valor econômico do patrimônio da biosfera destruída por essa atividade" (MARQUES, 2015, p. 485).

A busca pela internalização dos custos ambientais não é compatível com a dinâmica capitalista, pois a externalização dos custos faz parte do processo de lucratividade e geração de capital. Neste sentido, o filósofo alemão Robert Kurz explica esta impossibilidade:

Todo o debate sobre o chamado "desenvolvimento sustentável" ignora o caráter do princípio abstrato da valorização e do crescimento, que não possui nenhum senso para as qualidades materiais, ecológicas e sociais e, por isso, é também completamente incapaz de tomá-las em consideração. Absurdo por inteiro é o projeto de querer que a economia industrial contabilize em seus balanços os custos da destruição da natureza que ela tem acumulado. A essência da economia industrial consiste, é claro, justamente no fato de externalizar sistematicamente os custos, que por fim já não podem mais ser pagos por nenhuma instância. Se ela devesse parar com isso, já não seria mais nenhuma economia industrial, e os recursos sociais para o "processo de metabolismo com a natureza" teriam de ser organizados em uma forma qualitativamente diferente. É uma ilusão que a economia industrial deva renegar seu próprio princípio. $O$ lobo não vira vegetariano, e o capitalismo não vira uma associação para a proteção da natureza e para a filantropia (KURZ, 2002, não paginado). 
Ademais, se a internalização fosse levada a efeito inviabilizaria a comercialização do produto, devido ao seu alto custo e consequentemente sua própria produção. Por exemplo, se o agronegócio brasileiro internalizasse os custos ambientais da degradação dos solos e recursos hídricos, da diminuição da biodiversidade, certamente, o produto não seria tão rentável (MARQUES, 2015, p. 486).

Embora a maioria dos doutrinadores ambientais nos países ricos do mundo ainda se esquivem de um confronto direto com o capitalismo e busquem formas de se esverdear e humanizar o capitalismo, por exemplo, com a internalização dos custos ambientais e sociais, o certo é que

As contradições e complexidades de realmente implementar uma nova maneira de precificar commodities, em um sistema no qual o lucro é o único deus e poder está nas mãos de pessoas que não têm interesse em fazer isso, torna tudo isso uma tarefa insuperável. Como David Harvey disse: "Se o capitalismo for forçado a internalizar" todos os custos sociais e ambientais que gera "vai sair do negócio. Essa é a verdade simples" (MAGOFF; FOSTER, 2011, p. 97) (tradução nossa)

Vale destacar que há um problema técnico: muitos dos danos ambientais são acumulativos no tempo, ou seja, são danos futuros, outros são insuscetíveis de cálculo como a perda da biodiversidade, a quantidade de plásticos nos oceanos, o número de espécimes da fauna mortos por plásticos, o número de pessoas mortas ou sofrendo com câncer em virtude de agrotóxicos.

Contudo, a própria lógica do princípio do poluidor-pagador está em se buscar a internalização dos custos ambientais no processo produtivo, como se o fato de o consumidor final pagar a mais pelo produto ou serviço fosse resolver o cerne da exploração capitalista da natureza.

Outra forma de compensar os danos ambientais é a adoção de mecanismos de redução de emissões, por exemplo, o REDD+ (Redução de Emissões provenientes do Desmatamento e da Degradação florestal mais conservação de estoques de carbono florestal, manejo sustentável de florestas e aumento de estoques de carbono florestal), contudo, estes esquemas de comercialização não oferecem incentivos para uma transição tecnológica de longo prazo, mas apenas ganhos financeiros imediatos, regidos pelo predomínio do valor de troca sobre o valor de uso (CUNHA, 2015, p. 91).

O quinto fator de insustentabilidade do capitalismo, relacionado aos investimentos em lobbies e em publicidade, indica que a real preocupação das grandes empresas a respeito da sustentabilidade decorre da imagem da empresa, e não com o meio ambiente. Assim, as medidas a serem tomadas são a criação de lobbies 
e investimento em publicidade, o que está longe da verdadeira preocupação com a natureza e com as presentes e futuras gerações.

Por exemplo, o agronegócio investe fortemente em campanhas publicitárias para se apresentar à sociedade como fonte de riqueza para o país, de modernização e desenvolvimento, atraindo deste modo a simpatia do público. Também se apropriou da linguagem dos movimentos sociais, como forma de esvaziar o sentido, necessidade e utilidade destes movimentos, enfraquecendo-os perante a sociedade.

Neste sentido,

Ainda que a reforma agrária continue sendo combatida com balas, falta de recursos e criminalização, hoje o que se coloca em questão é a necessidade da sua existência. O agronegócio se apropriou da linguagem dos movimentos sociais e hoje incorpora todas as "promessas" que a reforma agrária carregava: não deixar a terra ociosa, produzir comida, cuidar do meio ambiente, integração campo e cidade, cultura e inclusão social (CHÃ, 2018, p. 185).

Próxima a esta lógica, o último aspecto da insustentabilidade do capitalismo diz respeito aos investimentos em censura e em campanhas publicitárias de desinformação. Estas táticas são antigas, Rachel Carson pode ser lembrada como exemplo de pesquisadora que teve seus estudos científicos contra o DDT desautorizados por "estudos" financiados pelas próprias indústrias de agrotóxicos.

Por isto, é fácil compreender o fato de as grandes corporações investirem mais em lobbies e campanhas publicitárias de desinformação do que em ações em prol de sustentabilidade, as quais são mais ações de marketing do que efetivamente ambientais (MARQUES, 2015, p. 488).

Os impactos negativos da exploração capitalista sobre o meio ambiente, são transformados pelos meios de comunicação em crescimento econômico e melhoria do bem-estar social, de forma que é mais fácil questionar a existência do planeta - e as alternativas para se colonizar outros planetas - do que a possibilidade de superação do sistema econômico capitalista (ALTVATER, 2018, p. 79).

De acordo com os professores franceses, François Chesnais e Claude Serfati, "na esfera do ambiente natural, o capital representa uma barreira, ou, mais exatamente, uma ameaça premente para a humanidade - e, no imediato, para certas parcelas específicas dessa -, mas não para o capital em si' (CHESNAIS; SERFATI, 2003, p. 42).

Portanto, é mais fácil se adaptar a um quadro nefasto de devastação ou conviver com a extinção de determinados grupos ou populações de animais humanos 
e não humanos do que o capital ser substituído universalmente em virtude das catástrofes ecológicas.

Isto porque "a insustentabilidade é constitutiva do capitalismo" (MARQUES, 2015, p. 597), não há como ter sustentabilidade diante de uma ordem jurídica que garante os interesses político-econômicos de uma pequena classe de pessoas em detrimento do bem-estar e dignidade, garantindo, ainda, que a primeira explore a segunda, para garantir a reprodução do capital (MARQUES, 2015, p. 597), em prejuízo da natureza e do equilíbrio ecológico do planeta.

Por isto, o capitalismo pode ser definido como um sistema de desenvolvimento insustentável, as razões podem ser encontradas na obra de Marx que pode ser chamada de crítica da economia política do desenvolvimento insustentável (FOSTER; CLARK; YORK, 2010, p. 430).

Cumpre indagar se o desenvolvimento sustentável será possível via reformas do capitalismo. Por exemplo, muitos órgãos ambientais oficiais ainda advogam a tese do controle de natalidade para aliviar a pressão sobre os recursos naturais, mas imagine-se, hipoteticamente, a população do planeta é reduzida pela metade, os problemas ambientais estariam resolvidos? E o que aconteceria em dois ou três meses depois, se for mantido o mesmo modo de produção? (PELIZZOLI, 1999, p. 104).

Aliás, indaga-se o próprio conteúdo do termo desenvolvimento sustentável, seu teor e sua abrangência, se é algo inerente ao capitalismo ou se é possível usálo na superação do capital.

Contudo,

A negação do termo desenvolvimento sustentável exige, ainda, esforços teóricos para a conceituação de um novo termo compatível com os anseios da crítica marxista. Identifica-se, igualmente, a possibilidade de ressignificação do termo associando-o a um novo modo de produção, superior ao capitalismo, mais ético, ecológico e voltado à superação das necessidades humanas e que respeite a simbiose metabólica entre homem e natureza. Tais esforços são vistos em Mészáros (2001) ao utilizarse, por exemplo, do conceito "igualdade substantiva" e em Löwy (2005) como ecossocialismo e ecomarxismo (FREITAS; NÉLSIS; NUNES, 2012, p. 48).

Para sanar e superar a crise ecológica são necessárias alternativas fora do capitalismo, ou seja, medidas que rompam com a estrutura social e econômica engessadas, por exemplo, através de um sistema social alternativo construído coletivamente e democraticamente, com enfrentamento das questões fundamentais pela ciência e filosofia calcadas em novas estruturas de saber (AZEVEDO, 2008, p. 
79), pois "não se pode sair da crise ambiental sem sair da crise do capitalismo; ou melhor, sem sair do capitalismo em crise" (SILVA, 2013, p. 129).

Neste sentido,

Uma reorganização de conjunto do modo de produção e de consumo é necessária, fundada em critérios exteriores ao mercado capitalista: as necessidades reais da população (não necessariamente "pagáveis") e a preservação do meio ambiente. Em outras palavras, uma economia de transição para o socialismo, "re-inserida" (como diria Karl Polanyi) no meio ambiente social, e natural, porque fundada na escolha democrática das prioridades e dos investimentos pela própria população - e não pelas "leis do mercado" ou por um politburo onisciente (LÖWY, 2005, p. 52-53).

Esta transição para uma sociedade não capitalista é articulada sob a forma do chamado ecossocialismo, uma corrente de pensamento e de ação ecológica que faz suas as aquisições fundamentais do marxismo, sem as antigas ideias produtivistas (LÖWY, 2005, p. 47), que poluiu o pensamento socialista no século passado.

A ideia de ecossocialismo, de acordo com Michael Löwy, implica uma radicalização da ruptura com a civilização material capitalista, pauta-se no reconhecimento de que as reformas capitalistas não são aptas à solução da crise ambiental e coloca-se como um conjunto de medidas sociais e ecológicas para construção de uma nova sociedade em um novo modo de produção não capitalista.

A utopia revolucionária de um socialismo verde ou de um comunismo solar não significa que não devamos agir desde agora. Não ter ilusões sobre a possibilidade de "ecologizar" o capitalismo não quer dizer que não possamos empreender o combate pelas reformas imediatas (LÖWY, 2005, p. 47).

O retorno ao marxismo clássico "com toda certeza é rigorosamente menos utópico do que pensar que o capitalismo pode oferecer - forçado ou não - qualquer saída para a crise ambiental" (DANTAS, 2012, p. 37).

No ecossocialismo as questões políticas, sociais e econômicas são decididas a partir da consideração da variável ambiental - da mesma forma que o Estado de Direito Ambiental almeja - de modo que haja um planejamento democrático local e nacional para a definição de quais produtos deverão ser subvencionados ou até mesmo distribuídos gratuitamente; quais opções energéticas deverão ser seguidas; como reorganizar o sistema de transportes, em função de critérios sociais e ecológicos e quais medidas devem ser tomadas para recuperação ambiental dos danos produzidos pelo capitalismo (LÖWY, 2005, p. 52-53).

O capitalismo se assenta sobre a acumulação e o crescimento constante da produção, contudo, tal lógica é inconciliável com a sustentabilidade, tendo em vista que a natureza é composta por elementos limitados, com um potencial limitado de regeneração. 
Neste sentido, Kohei Saito destaca a insustentabilidade do capitalismo:

De acordo com a opinião popular de que a produção sustentável é possível com base em mecanismos de mercado, a teoria do valor de Marx também demonstra de maneira convincente que o capital contradiz a limitação fundamental das forças e recursos naturais por seu impulso à autovalorização infinita. Essa é a contradição central do modo de produção capitalista, e a análise de Marx visa discernir os limites desse impulso incomensurável para a acumulação de capital dentro de um mundo material (SAITO, 2017, p. 259) (tradução nossa).

É imprescindível que a lógica produtiva, acumulativa e exploratória seja revista e alterada, pois o capitalismo é incompatível com o equilíbrio ecológico e a preservação da natureza, sendo necessária uma nova forma de organização social e produtiva que seja sustentável ambientalmente, economicamente e socialmente.

Em suma, é preciso uma mudança de rumo. Além de um forte decrescimento, é urgente diminuir o grau de desigualdade existente entre e dentro dos países. A humanidade precisa continuar reduzindo a pobreza, mas deve se focar mais na diminuição das desigualdades sociais e menos no crescimento quantitativo da economia. $O$ crescimento deve também ficar contido dentro das fronteiras planetárias, sem comprometer a biocapacidade da Terra e a biodiversidade das espécies. O "sistema de produção e consumo hegemônico" (capitalista ou socialista) não consegue ser, ao mesmo tempo, socialmente justo e ambientalmente sustentável. Por isso, é impossível que esse modelo, tal como o conhecemos, mantenha de pé as três bases do tripé da sustentabilidade, que na verdade se transformou em um trilema (MARTINE; ALVES, 2015, p. 456).

Não é possível um modelo de produção que gere pobreza, desigualdade social e um padrão de produção que consuma além dos limites do planeta, seja considerado sustentável e não há como ter um desenvolvimento sustentável sem uma forma de produção sustentável, da mesma maneira que não há como se ter um desenvolvimento sustentável com um desenvolvimento rural insustentável.

Por fim, importante consignar as críticas que apontam o desenvolvimento sustentável como uma estratégia de reprodução do capitalismo, sob um discurso universalista de futuro comum (SILVA, 2009, p. 65), o qual não aponta modelos, nem formas, nem crítica a exploração capitalista, pelo contrário, busca-se formas conciliatórias de promover o inconciliável: proteção à natureza e crescimento econômico.

\section{AS CONTRADIÇÕES ENTRE CAPITALISMO E NATUREZA}

A segunda contradição do capitalismo apresentada por James O'Connor, em 1988, no primeiro número da revista por ele fundada - Capitalism, Nature, Socia- 
lism: A Journal of Socialist Ecology-, diz respeito às condições naturais de produção, aos custos de produção e a relação entre produção e natureza, o que forneceu a base conceitual e crítica para que os ecomarxistas teorizassem sobre a relação contraditória entre capital e meio ambiente, a partir da obra de Marx.

James O'Connor apresenta as barreiras impostas pela natureza ao crescimento econômico como a segunda contradição do capitalismo. A primeira contradição reside na relação capital-trabalho, que, para O'Connor, estaria superada diante da importância e gravidade desta segunda contradição (HARVEY, 2013, p. 308).

A primeira contradição do capitalismo é trabalhada por Marx na análise da exploração do trabalho, expressando o poder social e político do capital sobre o trabalho e a tendência constante de crise do capital diante da superprodução. Assim, "a primeira contradição do capitalismo é interna ao sistema; não tem nada a ver com as condições de produção, sejam elas interpretadas economicamente ou em termos sociopolíticos" (O'CONNOR, 2001, p. 13) (tradução nossa).

Contudo, não se pode perder de vista que o próprio Marx, já advertia para a exploração da natureza pela sociedade capitalista:

A burguesia, em seu domínio de classe de apenas um século, criou forças produtivas mais numerosas e mais colossais do que todas as gerações passadas em seu conjunto. A subjugação das forças da natureza, as máquinas, a aplicação da química na indústria e na agricultura, a navegação a vapor, as estradas de ferro, o telégrafo elétrico, a exploração de continentes inteiros, a canalização dos rios, populações inteiras brotando da terra como por encanto - que século anterior teria suspeitado que semelhantes forças produtivas estivessem adormecidas no seio do trabalho social? (MARX; ENGELS, 2010, p. 44).

Para John Bellamy Foster, a primeira contradição do capital pode ser chamada de lei geral absoluta da acumulação capitalista e a segunda contradição de lei geral absoluta da degradação ambiental sob o capitalismo (FOSTER, 1993, p. 167).

A teoria da segunda contradição revela o caráter autodestrutivo do capitalismo em sua relação com o meio ambiente, "é uma apropriação autodestrutiva, dado que o capital avança na exploração e degradação do meio ambiente, até defrontar-se com limites físicos por ele mesmo criados" (MONTIBELLER-FILHO, 2000, p. 121).

Para ilustrar tal situação, podem ser elencados os casos de apropriação gratuita de recursos hídricos; o processo de desertificação dos solos, na agricultura moderna; a extinção de espécies de flora e fauna em virtude do avanço da fronteira 
agrícola; a mineração e seus impactos socioambientais, são alguns exemplos de formas com que o capitalismo usa a natureza no processo produtivo destruindo-a e gerando graves danos sociais e ambientais, os quais, inclusive impactarão no processo produtivo.

No capitalismo os elementos da natureza passam a ser tratados como "recursos naturais", ou seja, sob uma valoração econômica dentro da cadeia produtiva, de modo que sirvam à redução dos custos de produção e a favoreçam o incremento do lucro pelo capitalista (QUINTANA; HACON, 2011, p. 442).

A segunda contradição do capitalismo envolve a relação entre sociedade capitalista e natureza, de modo que não há como haver uma verdadeira política de preservação da natureza num modo de produção que parte da exploração ilimitada dos recursos naturais.

Assim, a causa desta segunda contradição "é o uso e a apropriação autodestrutiva da força de trabalho, do espaço e da natureza externa, o ambiente. A crise atual da saúde, da instrução e da família, a crise urbana e a ecológica exemplificam esta autodestrutividade" (O'CONNOR, 1993, p. 41).

A teoria da segunda contradição "conduz a conclusão de que os preceitos de equidade social, econômica e ambiental, sincrônica e diacrônica, inerentes ao paradigma do desenvolvimento sustentável são inatingíveis no sistema capitalista" (O'CONNOR, 1993, p. 131), haja vista que sua forma de produzir está calcada na exploração e esgotamento da natureza e na geração de custos sociais.

Marx foi um dos primeiros pensadores a expor a relação metabólica existente ente seres humanos e natureza, destacando que o avanço do capitalismo e da produção agrícola em alta escala rompem com este metabolismo, o que ele chamou de ruptura metabólica.

Neste sentido,

Não é a unidade do ser humano vivo e ativo com as condições naturais, inorgânicas, do seu metabolismo com a natureza e, em consequência, a sua apropriação da natureza que precisa de explicação ou é resultado de um processo histórico, mas a separação entre essas condições inorgânicas da existência humana e essa existência ativa, uma separação que só está posta por completo na relação entre trabalho assalariado e capital (MARX, 2011, p. 401).

A ruptura metabólica, portanto, indica o rompimento da relação entre natureza e sociedade capitalista através da alienação do trabalho e da própria natureza (FOSTER, 2014, p. 222), cuja troca energética entre seres humanos e natureza deixa de ser exercida diretamente pelas pessoas, passando a ser intermediada pela indústria de exploração agrícola, o que coloca em risco a capacidade produtiva dos 
solos, análise já feita por Marx ao apontar sobre a necessidade de se proteger a terra para as presentes e futuras gerações e não apenas sob o prisma da propriedade privada (MARX, 2013, p. 836).

Por esta razão é necessário repensar novas formas sociais e de produção, para além do capitalismo, superando a contradição entre exploração capitalista e equilíbrio ecológico, o que mostra o Estado de Direito Ambiental mais como sonho do que realidade. O ecossocialismo busca aproximar as perspectivas de luta contra a exploração do trabalho com a luta em defesa do meio ambiente, superando a segunda contradição do capitalismo.

Deste modo, a questão ecológica se coloca como o grande desafio para a renovação do pensamento marxista no século XXI e para a abertura do caminho para o socialismo, através da satisfação das necessidades sociais, a redução da jornada de trabalho e a orientação do progresso compatível com o equilíbrio ecológico (LÖWY, 2005, p. 38-39).

O ecossocialismo basicamente busca a construção de uma nova sociedade pautada no controle democrático, na igualdade social, no predomínio do valor de uso sobre o valor de troca, na propriedade coletiva dos meios de produção, no planejamento democrático que permita a sociedade e às pessoas decidirem o próprio destino, através da escolha do que e como produzir (LÖWY, 2009, p. 36).

Destarte, implica uma crítica profunda e radical das experiências e das concepções tecnocráticas, burocráticas e não ecológicas de construção do socialismo, além de uma reflexão crítica sobre a tradição marxista sobre a questão do meio ambiente (LÖWY, 2013, p. 82), almeja a organização da produção de acordo com as necessidades sociais e a capacidade da natureza, permitindo que as pessoas possam se tornar sujeitos ativos de suas próprias vidas e em harmonia com o ambiente em que vivem.

\section{CONSIDERAÇÕES FINAIS}

O Estado de direito ambiental, por mais bem-intencionado que seja em defender o meio ambiente, possui limites de atuação restritos aos quadrantes do capitalismo, sendo que as verdadeiras medidas em defesa do meio ambiente - aquelas que buscam a reparação da falha metabólica - exigem a superação do capitalismo. 
Um Estado de direito ambiental se pauta em um modelo de desenvolvimento sustentável, mas no capitalismo não há sustentabilidade, tendo em vista a necessidade de crescimento ilimitado, a exploração dos seres humanos e da natureza, a mercantilização da natureza sob o valor de troca, o uso ilimitado da terra em busca de lucro são exemplos de sua insustentabilidade.

Contudo, ter em mente os limites da efetividade da proteção ambiental no capitalismo não significa abandonar todo e qualquer projeto de proteção ambiental, mas se deve ter em mente que um Estado capitalista ambiental não é a solução para a crise ambiental, mas apenas um caminho provisório e paliativo, que não pode ser desprezado, dado a gravidade dos problemas ambientais.

Para merecer a adjetivação de sustentabilidade, é necessário interligar aspectos econômicos, sociais e ambientais, de modo que não é possível um desenvolvimento sustentável com desigualdade social, miséria e exaurimento dos recursos naturais.

Porém, no capitalismo é necessária a existência de grupos marginalizados e sem trabalho, conhecidos como exército industrial de reserva e lumpemproletariado, com a finalidade de regular o valor da mão-de-obra, em um patamar que garanta a lucratividade por parte dos detentores dos meios de produção.

Destarte, a sustentabilidade em sua tripla dimensão não se mostra possível no capitalismo, pois ele se mantém através de um processo dinâmico de acumulação, o qual é portador de crises e colapsos, tendo em vista que o crescimento capitalista independe das necessidades humanas é guiado pelas mistificações fetichistas, de modo que a busca incessante de crescimento e produtividade é incompatível com o objetivo de sustentabilidade.

A vocação capitalista para a produção ilimitada esgota os bens naturais e explora o trabalho humano, tornando este modo de produção insustentável, por não promover justiça social, dignidade aos trabalhadores e preservação do equilíbrio ecológico dos ecossistemas.

Portanto, não é possível que um modelo de produção que gere pobreza, desigualdade social e um padrão de produção que consuma além dos limites do planeta, seja considerado sustentável. Do mesmo modo, não é possível se ter um desenvolvimento sustentável com uma forma de produção insustentável, logo, a produção agrícola capitalista, diante de todos os problemas ambientais causados, não é sustentável. 
Para solucionar a crise ecológica são necessárias alternativas fora do capitalismo, que rompam com a estrutura social e econômica engessadas, por exemplo, através de um sistema social alternativo construído coletivamente e democraticamente, que possa representar a liberação do pensamento e a experiências de novas formas organizacionais que superem as contradições inerentes a exploração capitalista da sociedade e da natureza.

\section{REFERÊNCIAS}

ALMEIDA, Jalcione. Da ideologia do progresso à idéia de desenvolvimento (rural) sustentável. In: ALMEIDA, Jalcione; NAVARRO, Zander (org.). Reconstruindo a agricultura: ideias e ideais na perspectiva do desenvolvimento rural sustentável. Porto Alegre: Editora da UFRGS, 1997.

ALTVATER, Elmar. Crítica da economia política na praia de plástico e o fetiche do capital no Antropoceno. Margem Esquerda:Revista da Boitempo, São Paulo, n. 31, p. 69-84, 2018.

AMADO, Frederico. Direito ambiental. 10. ed. Salvador: JusPodivm, 2019.

ANDRIOLI, Antônio Inácio. A atualidade de Marx para o debate sobre tecnologia e meio ambiente. Crítica Marxista, Campinas, n. 27, p. 11-25, 2008.

ARAGÃO, Alexandra. O Estado de Direito Ecológico no antropoceno e os limites do planeta. In: LEITE, José Rubens Morato; DINNEBIER, Flávia França. Estado de Direito Ecológico: conceito, conteúdo e novas dimensões para a proteção da natureza. São Paulo: Instituto O direito por um Planeta Verde, 2017.

AZEVEDO, Plauto Faraco de. Ecocivilização: ambiente e direito no limiar da vida. 2. ed. São Paulo: RT, 2008.

BENJAMIN, Antônio Herman de Vasconcellos e. O Estado teatral e a implementação do direito ambiental. Direito, agua e vida. v. 1, [s. I.]: 2010, p. 7. Disponível em: https://bdjur.stj.jus.br/jspui/bitstream/2011/30604/Estado_Teatral_Implementa\%C3\%A7 \%С3\%A30.pdf. Acesso em: 02 ago. 2020.

BRASIL. Supremo Tribunal Federal (pleno). Ação Direta de Inconstitucionalidade $n^{\circ} 4901$. Relator: Min. Celso de Mello, 28 de fevereiro de 2018. Brasília: Supremo Tribunal Federal. Disponível em: http://www.stf.jus.br/arquivo/cms/noticiaNoticiaStf/anexo/VotoMinistroCMADI4.901 DF.pdf. Acesso em: 11 mar. 2019.

CAMARGO, Ana Luiza de Brasil. Desenvolvimento sustentável: dimensões e desafios. Campinas: Papirus, 2003.

CANOTILHO, José Joaquim Gomes. Estado constitucional ecológico e democracia sustentada. In: FERREIRA, Heline Sivini; LEITE, José Rubens Morato (org.). Estado de direito ambiental: tendências, aspectos constitucionais e diagnósticos. Rio de Janeiro: Forense Universitária, 2004. 
CANOTILHO, José Joaquim Gomes. Direito Constitucional ambiental português e da União Europeia. In: CANOTILHO, José Joaquim Gomes; LEITE, José Rubens Morato (org.). Direito Constitucional Ambiental brasileiro. São Paulo: Saraiva, 2007.

CAPRA, Fritjof. Ponto de mutação: a ciência, a sociedade e a cultura emergente. São Paulo: Cultrix, 2006.

CHÃ, Ana Manuela. Agronegócio e indústria cultural: estratégias das empresas para a construção da hegemonia. São Paulo: Expressão Popular, 2018.

CHESNAIS, François; SERFATI, Claude. "Ecologia" e condições físicas da reprodução social: alguns fios condutores marxistas. Crítica Marxista, Campinas, n. 16, p. 39-75, 2003.

CECHIN, Andrei Domingues \& VEIGA, José Eli da. A economia ecológica e evolucionária de Georgescu-Roegen. Revista de Economia Política, São Paulo, v. 30, n. 3, jul./set. 2010. Não paginado.

COMISSÃO MUNDIAL SOBRE MEIO AMBIENTE E DESENVOLVIMENTO. NOSSO futuro comum. 2. ed. Rio de Janeiro: Editora da Fundação Getúlio Vargas, 1991.

CUNHA, Daniel. O Antropoceno como fetichismo. Revista Continentes, Seropédica, ano 4, n. 6, p. 83-102, 2015.

DANTAS, Gilson. Natureza atormentada, marxismo e classe trabalhadora. 2. ed. Brasília: Centelha Cultural, 2012.

FOLADORI, Guillermo. Avanços e limites da sustentabilidade social. Revista Paranaense de Desenvolvimento, Curitiba, n. 102, p. 103-113, jan./jun. 2002.

FOLADORI, Guillermo. Marxismo e meio ambiente. Revista de Ciências Humanas, Florianópolis, n. 25, p. 82-92, abr. 1999.

FOSTER, John Bellamy. La ley general absoluta de la degradacion ambiental en el capitalismo. Ecología Política, Barcelona, n. 4, p. 167-169, 1993.

FOSTER, John Bellamy; CLARK, Brett; YORK, Richard. The ecological rift: capitalism's war on the Earth. New York: Monthly Review Press, 2010.

FOSTER, John Bellamy. A ecologia de Marx: materialismo e natureza. Rio de Janeiro: Civilização Brasileira, 2014.

FOSTER, John Bellamy. Marxismo e Ecologia: fontes comuns de uma Grande Transição. Lutas Sociais, São Paulo, v. 19, n. 35, p. 80-97, jul./dez. 2015.

FREITAS, Rosana de Carvalho Martinelli; NÉLSIS, Camila Magalhães; NUNES, Letícia Soares. A crítica marxista ao desenvolvimento (in)sustentável. Revista Katálysis, Florianópolis, v. 15, n. 1, p. 41-51, jan./jun. 2012.

HARVEY, David. Para entender o capital:livro I. São Paulo: Boitempo, 2013.

HIRSCH, Joachim. Teoria materialista do Estado. Rio de Janeiro: Revan, 2010.

KRELL, Andreas J. O Estado ambiental como princípio estrutural da Constituição brasileira. In: LEITE, José Rubens Morato; DINNEBIER, Flávia França. Estado de Direito 
Ecológico: conceito, conteúdo e novas dimensões para a proteção da natureza. São Paulo: Instituto O direito por um Planeta Verde, 2017.

KURZ, Robert. O desenvolvimento insustentável da natureza. O Beco, [s. I.], out. 2002. Disponível em: http://www.obeco-online.org/rkurz108.htm. Acesso em: 22 maio 2020. Não paginado.

LÖWY, Michael. Crise ecológica, crise capitalista, crise de civilização: a alternativa ecossocialista. Caderno CRH, Salvador, v. 26, n. 67, p. 79-86, jan./abr. 2013.

LÖWY, Michael. Ecossocialismo e planejamento democrático. Crítica Marxista, Campinas, n. 28, p. 35-50, 2009.

LÖWY, Michael. Ecologia e socialismo. São Paulo: Cortez, 2005.

MAGOFF, Fred; FOSTER, John Bellamy. What every environmentalist needs to know about capitalism: a citizen's guide to capitalism and the environment. New York: Montly Review Press, 2011.

MARX, Karl. Grundrisse: manuscritos econômicos de 1857-1858: esboço da crítica da economia política. São Paulo: Boitempo; Rio de Janeiro: UFRJ, 2011.

MARX, Karl; ENGELS, Friedrich. Manifesto comunista. São Paulo: Boitempo, 2010.

MARX, Karl. O capital: crítica da economia política: livro III: o processo global da produção capitalista. São Paulo: Boitempo, 2013.

MÉSZÁROS, István. O desafio do desenvolvimento sustentável e a cultura da igualdade substantiva. Texto lido na conferência da Cúpula dos Parlamentares Latino-Americanos.

Caracas, 2001. Disponível em: https://resistir.info/mreview/desenvolvimento_sustentavel.html. Acesso em: 18 jun. 2020. Não paginado.

MÉSZÁROS, István. A única economia possível. Resistir.info, [s. l.]: [20-?]. Disponível em: http://resistir.info/meszaros/only_viable_economy_p.html. Acesso em: 02 jun. 2020. Não paginado.

MARTINE, George; ALVES, José Eustáquio Diniz. Economia, sociedade e meio ambiente no século 21: tripé ou trilema da sustentabilidade? Revista brasileira de Estudos de População, Rio de Janeiro, v. 32, n. 3, p. 433-460, 2015.

MARQUES, Luiz. Capitalismo e colapso ambiental. Campinas: Unicamp, 2015.

MONTIBELLER-FILHO, Gilberto. Ecomarxismo e capitalismo. Revista de Ciências Humanas, Florianópolis, n. 28, p. 107-132, out. 2000.

O'CONNOR, James. Capitalismo e meio ambiente. Novos Rumos, Marília, v. 21, n. 8, p. 40-43, 1993.

O'CONNOR, James. Causas naturales: Ensayos de marxismo ecológico. México: Siglo XXI Editores, 2001.

OXFAM. Uma economia para os 99\%. Documento informativo: Relatório Davos (2017). 16 jan. 2017. Disponível em: https://www.oxfam.org.br/publicacoes/uma-economia-paraos-99. Acesso em: 20 jul. 2020. 
PACHECO, Cláudio Gonçalves. As desventuras de um Estado de Direito Ambiental. Revista de Informação Legislativa, Brasília, ano 52, n. 205, p. 297-317, jan./mar. 2015.

PELIZZOLI, Marcelo Luiz. A emergência do paradigma ecológico: reflexões éticofilosóficas para o século XXI. 2. ed. Rio de Janeiro: Vozes, 1999.

QUINTANA, Ana Carolina; HACON, Vanessa. O desenvolvimento do capitalismo e a crise ambiental. O Social em Questão, Rio de Janeiro, ano XIV, n. 25/26, p. 427-444, 2011.

SAITO, Kohei. Capital, nature, and the unfinished critique of political economy. New York: Monthly Review Press, 2017.

SHIVA, Vandana. Guerras por água: privatização, poluição e lucro. São Paulo: Radical Livros, 2006.

SILVA, Maria Beatriz Oliveira da. Crise ecológica e crise(s) do capitalismo: o suporte da teoria marxista para a explicação da crise ambiental. Revista Veredas do Direito, Belo Horizonte, v. 10, n. 19, p. 115-132, jan./jun. 2013.

SILVA, Maria Beatriz Oliveira da. Desenvolvimento (sustentável) no Brasil de Lula: uma abordagem jurídico-ambiental. Santa Cruz do Sul, 2009. 